La gestión de la radio debe ser amorosa con la gente

Carlos Ulanovsky - Carlos Milito

Question/Cuestión, Vol. 2, N 66, Agosto 2020

ISSN 1669-6581

https://perio.unlp.edu.ar/ojs/index.php/question/index

IICom-FPyCS-UNLP

\section{LA GESTIÓN DE LA RADIO DEBE SER AMOROSA CON LA GENTE}

\section{RADIO MANAGEMENT MUST BE LOVING TO THE PEOPLE}

\section{Carlos Ulanovsky}

Periodista y escritor

Actualmente conduce Reunión cumbre por AM 750

\section{Carlos Milito}

https://orcid.org/0000-0002-5874-6951

cmilito@perio.unlp.edu.ar

Magister en Comunicación y gestión de procesos comunicacionales

Profesor Titular del Taller de producción de contenidos y narrativas sonoras y

radiales

Director de la Especialización en Comunicación radiofónica Integrante del IICom (Instituto de Investigaciones en Comunicación) 
FPyCS-UNLP

Coordinador de 1894radioonline de Villa Elisa, Provincia de Buenos Aires Locutor comercial de Relatores. Transmisiones Deportivas por la app y AM530

Somos Radio

\section{Resumen}

Recorre la historia de la radio, asume una relación existencial con el medio. La gestión, la producción, el conocimiento y la creatividad. El futuro de la radio.

\section{Palabras clave}

Radio, Historia, Gestión, Conocimiento

\section{Abstract}

Go through the history of radio, assume an existential relationship with the medium. Management, production, knowledge and creativity. The future of radio.

\section{Keywords}

Radio, History, Management, Knowledge

\section{Enlace}

https://go.ivoox.com/rf/55578354 